\title{
Global Citizens for the Twenty-First Century: The Role of International Partnerships in University Education
}

\author{
Feridun Hamdullahpur
}

\section{Introduction}

The scale of disruption that our world faces from geopolitical to socioeconomic perspectives is vast. No single researcher, university or nation can achieve a breakthrough solution alone. The challenges are too complex, and finding success is only possible when we work together as a global community of educators, researchers and influencers.

At the heart of this is the need to collaborate across borders, languages, industries and disciplines. The challenges and opportunities in our disruptive world are only becoming more complex due to the acceleration of new technology, an ageing population in the West, an increasingly turbulent geopolitical landscape and more.

This chapter will explore the role international partnerships have for universities and how they educate, research and impact a disruptive future.

Cross-discipline cooperation has long been the focus of many institutions to increase the impact of research and the strength of our students' education. This approach can also be taken through international partnerships that leverage the combined power of talent, resources and vision that spans national boundaries and cultures. Our increasingly globalized world offers a range of opportunities for university education to grow and flourish at the individual level, institutional level and the national and global levels.

It is vital that international partnerships also bring together a range of partners that intersect with all aspects of our society. This means broadening the scope of traditional partnerships between universities to include partners in government, industry and Non-Governmental Organizations (NGOs).

And, how we develop international work-integrated learning opportunities will make the difference in our

F. Hamdullahpur $(\bowtie)$

University of Waterloo, Waterloo, Canada

e-mail: president@uwaterloo.ca ability as universities to develop global talent when we need their leadership the most.

\section{Achieving the Three Levels of Collaboration Success}

Internationalization within post-secondary institutions has evolved into a mosaic of programs and partnerships that look nothing like those seen in past decades [1]. Each international partnership is unique and has developed to suit a specific need for the institution, researchers or students involved.

A university's expertise, scope and goals are individual to their community of students, faculty and community members. While each collaboration has individual characteristics that make it ideal for both or multiple parties involved, achieving wide-ranging success in international partnerships means developing partnerships that have an Individual Impact, Institutional Impact and a National and Global Impact.

Implementing actionable programs that touch on each of these levels is vital in creating lasting and comprehensive international partnerships for universities. Because of the central role universities play in educating the world's citizens and their leadership in scientific, technological and policy research, achieving success at each level is the ideal approach for broad impact.

\subsection{Individual Impact}

The Individual Impact of international partnerships most often comes in the form of student exchanges. The intrinsic characteristic of universities viewing the free flow of ideas that transcend borders, conflict and cultures as being very valuable has made international exchanges standard practice at most institutions around the world. As our world has become smaller and more globalized, the value of international experiences for students has only increased. 
Increasing the ability of students to gain a global perspective through short-term and long-term exchanges offers valuable experiences for students that transcend their learning in the classroom. Offering and hosting exchange students from partnering institutions from around the world creates a lasting impact on the students involved that is immediately felt upon the completion of their education.

A survey of Asian companies found that $57 \%$ of surveyed companies agreed that hiring international talent is very important or somewhat important [2]. The demand is there for the talent, and students understand that there is significant value in international exchanges that can increase their career prospects.

The Erasmus Impact Study [3], which surveys European Union students in exchange programs, found in 2013 that the rate of unemployment for students who had studied abroad was $23 \%$ lower than those who had remained in their home country. This is not insignificant in the minds of students who are looking to their future prospects for employment throughout their university career.

Developing exchange offerings for students ultimately depends on establishing positive relationships with partner institutions with similar academic and research programs. Creating a framework that is mutually beneficial for both institutions and students create a good foundation for long-term relationships. To make these relationships and experiences as positive as possible, each university must ensure a cohesive process of bringing international students into their campus community.

There are also typical barriers international students face that need to be addressed to ensure a successful student exchange for all parties involved. These considerations include most pressingly, financial limitations that limit the ability for students to explore the world. Considerations also include screening for positive academic prerequisites, so students have the educational background needed to succeed, language support for those students arriving in a country that is not their native tongue, community integration services that bring exchange students into the greater university community, and the student mental health and wellness supports needed to serve international exchange students.

Many of these elements and expectations should be well-defined in the student exchange agreement to ensure that the responsibilities of each institution are clear to each party. Institutions can begin the exploration of such exchanges through a preliminary memorandum of understanding (MoU), but a formal agreement that is signed between both parties is necessary in the end.

Given different national and institutional cultures are at play when developing these agreements, what is customary at one institution or in one country may not be at another. Establishing expectations for each party ahead of time will help mitigate disagreements and possible legal issues that may arise in the future.

Embracing exchange students and the potential they have to add to the diversity of ideas and perspectives will strengthen the hosting university as the blending of cultures and experiences spreads throughout the domestic student population. The links that are created across nations and institutions start at the individual level and can last lifetimes. The impact is significant on the individual student involved, but also lends to what is possible at the institutional level when international partnerships are established.

\subsection{Institutional Impact}

The second level of international collaboration that is integral to developing successful partnerships is those that have an Institutional Impact. Institutional Impact collaborations are primarily found at the research level. This includes, but is not limited to, joint research projects, co-authoring of research papers and the sharing of resources through joint research grants and research equipment use.

With the ever-present challenge of raising funds and the resources needed for any number of research projects, it can be difficult for any institution to have the equipment and field expertise to meet the curiosity and vision of their researchers. To meet this demand, like-minded universities from around the world can find common ground and partner on projects and work together towards discovery.

This can be joint research projects between disciplines to maximize institutional expertise or formally pooling resources to fund large-scale joint projects on previously agreed upon areas of focus. By building complementary agreements that lean into the strengths of each institution, there are more opportunities to make an impact across disciplines and fields. This can bolster the output from each institution that would not have been possible prior to the agreements.

Assessing the success of these programs can be established through several performance indicators that are individual to each project and institution. Traditional indicators include the number of joint research papers that are authored between the partnering institutions and the number of joint research grants awarded through the added strength of the collaboration.

Further to the partnerships between institutions is the addition of collaborations between universities and industry partners. The development of international research agreements between universities and businesses that are not domestically connected is becoming a commonplace. The transfer of ideas and innovations through collaborative R\&D between academia and industry lends to an impact at the institutional level that creates generally positive outcomes for everyone involved. 
According to a study in The Journal of Technology and Transfer, industry partners enjoy the benefit of having access to groundbreaking research and talent pools, and universities find a source of revenue to fund graduate student work and often the addition of needed equipment. This makes both parties likely to expand on more project collaborations in the future [4].

It was pointed out in the Individual Impact section the impact student mobility and exchanges can have on those students taking part in a cross-cultural experience. A similar benefit can be found at the Institutional Impact level through staff exchanges. Staff exchanges between institutions and cultures can have a fundamental impact on the innovative ability of any university through the exploration of how their peers from around the world face common challenges in their work.

These exchanges can include a university's communications team travelling to a partnering institution to collaborate and explore joint projects or a staff member travelling to another university to speak with and/or shadow a peer of theirs to experience their culture and share industry best practices. Universities hold a tremendous amount of talent in their staff and the power of collaboration amongst this community group can be leveraged both for closer relationships between individuals and to make improvements at an institutional level.

Universities have an opportunity to add to their research capabilities through collaborations that aim to bring like-minded institutions and researchers together. The impact of these collaborations can be highly valuable. In addition, through partnerships with the private sector and embracing an entrepreneurial spirit of discovery and creation, universities can be impactful on a whole other level that has significant implications nationally and globally.

\subsection{National and Global Impact}

Remaining at this level of international cooperation can be both fruitful and limiting at the same time. Individual and Institutional Impact keep the emphasis of positive collaborations within the realm of student and university. While these programs can create strong impacts on the personal and institutional level, there is further room to grow international collaborations so they can have national and global impacts.

International programs that promote entrepreneurial enterprises and the development of university intellectual property into commercialized ventures will have the ability to shape and impact society at a far greater scale than institutional and individual levels. For many institutions, this can be a challenge to implement as it is counter to their established practices and can face resistance at a faculty level.
A number of universities around the world are making entrepreneurship a priority for their students, but what is often lost is the importance of international collaborations in developing technology and intellectual property (IP) that can have a global impact.

Growth within regional and global economies can be produced through a university's dedication to supporting entrepreneurship and innovative IP policy for students and researchers [5]. Coordinating with international partners through joint ventures and research projects with an eye on the commercialization of research makes the impact far greater than the act of discovery. Bringing innovations to the world and understanding global markets through international partnerships bring an element of coordination and global experience that students, faculty and alumni can use to their advantage down the road.

Creating international entrepreneurial experiences for students and faculty is a key in having a national and global impact that creates economic prosperity and provides a primer for future technological and scientific discoveries.

Challenges to the establishment of global ventures rest at the institutional and legal limitations of each partnering organization. Each university must adhere to a form of creator-owned IP policy that removes the barrier of who owns the IP by keeping the ownership with the researchers involved and not the university. This will fuel the desire and opportunity for more researcher-driven ventures as it incentivizes commercialization and limits any legal issues that may come to pass between partnering institutions.

It is equally as important that the partnering organizations promote entrepreneurship at their universities at a fundamental level. A creator-friendly IP policy is vital towards promoting entrepreneurship but additional supports such as mentoring, commercialization expertise and basic startup programs for researchers are integral to future success. Adding international experiences through research partnerships and international work-integrated learning experiences for students, such as cooperative education job placements, contributes to the future impact of international partnerships.

It is understandable that every university within their national border would want to contribute and be a part of building a strong, healthy economy through talent, knowledge and, more so, the integration of the two in the simplest form of entrepreneurship. However, many large-scale challenges (i.e. water scarcity, climate change, artificial intelligence) are of a global scale, and we need to understand and accept the importance and value of sharing and building solutions together with other nations through collaborations.

Of the nearly 200 million students who are enroled in universities and colleges worldwide, about 5 million of them study at institutions outside of their home countries [6]. This 
provides a tremendous amount of mobility of knowledge, culture, global awareness and opportunity.

And, since the world is in great need of collective learning from one another and building healthy economies worldwide, what could be a better opportunity to collaborate globally to achieve prosperity for all?

\section{The Wide Range of University Partnerships}

Knowing that there is a range of international collaborations possible for a university broadens its ability to find the perfect institutional fit whether it is with another university, private enterprise, government or NGO. Partnerships are not limited to what can be traditionally thought of as academic exchanges of students and ideas, but can also be viewed as an act of collaboration that creates something neither organization could achieve on its own impact.

It is vital to weave collaborations together and build a network of cooperation that is complementary to all parties. Given the central role of universities to be centres of excellence where society comes to educate the next generation and find the discoveries that will drive future prosperity, ensuring all avenues of international cooperation are leveraged will strengthen outcomes and contribute a level of diversification needed in our complex, globalized economy [7].

There are several examples of these varying partnerships that can be found at the University of Waterloo.

\subsection{Soochow University, University of Waterloo and Suzhou Industrial Park Joint Institute of Research and Education on Nanotechnology}

International partnerships can be tailored for comprehensive impact. While these partnerships add new layers of complexity to both build and sustain, they also have the opportunity to create positive outcomes that cross borders even outside of academia.

The strong and productive research partnership between the University of Waterloo's Waterloo Institute for Nanotechnology (WIN) and the Soochow University started in 2011 when Soochow University, the University of Waterloo and the Suzhou Industrial Park (SUN-WIN-SIP) initiated a Joint Institute of Research and Education. The objectives of the Joint Institute are to enable faculty at both institutions to engage in research collaborations, foster scholar exchange and stimulate entrepreneurship and innovation in nanotechnology [8].

The partnership is made up of several programs and agreements that blend research, education and commercialization that are aided by SIP and Waterloo's spirit of entrepreneurship and creator-friendly IP policy.
The research collaboration has shown to be productive as SUN and SIP have sponsored 24 collaborative SUN-WIN research projects in each of the four key theme areas of nanotechnology, namely nanoinstrumentation, nanobiosystems, nanoelectronics and nanomaterials development, since April 2012.

The first round of funding sponsored 12 projects, ten of which received 450,000 RMB (approximately \$70,000 CAD) and two of which received 750,000 RMB (approximately \$150,000 CAD) over three years. In 2013, seven additional projects were awarded 450,000 RMB each, and in 2015 five projects received the same.

During the initial phase of the collaboration process, Soochow University's Technology Transfer Office visited WIN in July 2012 to learn more about the University of Waterloo's commercialization practices, IP policies, entrepreneurship and faculty support. The University of Waterloo has a progressive creator-owned IP Policy that is unique amongst most universities around the world and has aided in Waterloo's researchers and students creating hundreds of startup ventures that include successful technology companies.

The partnership also brought graduate and undergraduate students into the agreement. Soochow University and WIN have signed agreements on collaborative educational programs for Soochow students interested in studying nanotechnology at the University of Waterloo, including the Doctoral program and the 3+1+1 joint Bachelor's/Master's program. In addition, WIN hosts several fourth-year Soochow students for a four-month research internship program which is sponsored by the China Scholarship Council.

This has allowed the University of Waterloo to attract top international graduate students to WIN and the university, and Soochow can offer their students the experience of studying at one of Canada's top nanotechnology labs.

Since the beginning of the nanotechnology collaboration between the University of Waterloo and Soochow, there has only been growth. These successes have also inspired the exploration of creating further agreements with additional fields of study, such as Energy and the Water Institute.

What began as an international research collaboration has flourished into a multidimensional partnership that has had fundamental Individual Impact, Institutional Impact and, with the focus on entrepreneurship, National and Global Impact.

\subsection{United Nations Sustainable Development Solutions Network}

As discussed in the previous sections, universities have a central role in bringing international partners from all sectors of society together to face some of the most pressing 
challenges facing our world. An example of this effort that can have far-reaching national and international implications can be found in the partnership the University of Waterloo established with the United Nations Sustainable Development Solutions Network (SDSN).

The SDSN is a global initiative by the United Nations dedicated to mobilizing the global community of scientific and technological talent to help promote the UN's 17 Sustainable Development Goals (SDGs) and help their nations meet their SDG targets. The majority of the work is done on the ground in regional and national SDSN hubs that can bring together those researchers, policy-makers and society members who wish to help reach their nation's SDG targets. All of this is done in an effort to accelerate an integrated approach to building a more sustainable world.

In May of 2018, the University of Waterloo became the founding institution of Canada's national SDSN hub: SDSN Canada. SDSN Canada is the country's hub of sustainability action that links hundreds of researchers and organizations that are dedicated to meeting Canada's SDG targets.

What the establishment of SDSN Canada at the University of Waterloo means for the institution is twofold. First, the University of Waterloo builds a stronger connection with a major international organization in the SDSN and also with the United Nations itself. Secondly, Waterloo becomes a national beacon, in academia, government and the rest of society, for the successful movement towards building a more sustainable world.

This increases the number of researchers, NGOs and universities from across Canada and the world which look to Waterloo as a leader in sustainability research and practices. Ten Canadian universities and NGOs have partnered with SDSN Canada in less than a year of operation [9]. These organizations are bringing their expertise and ideas to the University of Waterloo because of the institution's international partnership.

National recognition is being paid to the University of Waterloo, but it is important to note that the university is also now linked with 24 other regional and national SDSN networks from around the world. These connections are more than reputational as they can act as greater opportunities for sharing best practices and they can potentially result in future international research projects.

While the university is seeing all of this activity, SDSN Global and the United Nations have found a dedicated and capable partner to lead their Canadian SDG efforts. It is a mutually beneficial partnership that has national and global benefits for the University of Waterloo, but this partnership was not accidental.

SDSN Canada rests within the University of Waterloo's Faculty of Environment. This is the largest Faculty of Environment in Canada with the capabilities and talent of few other institutions within Canada, but the faculty also had the forethought to apply to SDSN Global to be SDSN Canada's founding institution to see what it could become.

The projects that will stem from SDSN Canada will make an impact on Canada's future prosperity, and it will do so because of this unique and successful international collaboration between universities and national and international NGOs.

\subsection{Risk Management, Economic Sustainability and Actuarial Science Development in Indonesia}

University partnerships can naturally take different forms with many different goals and partners. Universities can not only partner with international institutions and governments, but also be an agent of global change with the support of their national government.

An example of this type of partnership can be found in the University of Waterloo's collaboration with the Department of Global Affairs Canada (GAC), international insurance companies Manulife Indonesia and Sun Life Asia and seven Indonesian universities to create Risk Management, Economical Sustainability and Actuarial Science Development in Indonesia (READI) [10]. With funding support from the GAC, Manulife and Sun Life, the READI project aims to establish Indonesia as a regional centre of actuarial excellence.

The University of Waterloo operates as the Canadian Executing Agency for the project through the area expertise of its Department of Statistics and Actuarial Science. As the executing agency, Waterloo's role in this multilateral, international partnership is to help train and facilitate long-lasting capacity within Indonesian universities to promote and train actuaries in their home institutions.

On a broader level, this partnership endeavours to increase the number and quality of Indonesian actuarial science graduates, strengthen the linkages between industry, government and educational institutions in support of actuarial science and risk management and deepen the understanding of actuarial science and risk management as a profession in Indonesia. This effort comes at a pivotal time in the South-Asian region.

Indonesia and the entire Ring of Fire region around the Pacific Ocean face natural disasters on a regular basis, such as the devastating tsunami that hit Indonesia in 2004. These incidents bring loss of life and loss of property at significant levels. The insurance and pension industry helps provide safety nets that keep losses from being overwhelming, which allow people to rebuild their lives following disasters, and helps people to build and protect prosperity.

Without actuaries, or without enough actuaries, the ability of poor and middle-income people to access insurance, 
pensions and retirement plans is compromised, leaving future prosperity in the wake of disasters uncertain. That is the situation in Indonesia.

The READI partnership crosses borders and industries, brings expertise and resources from the established Department of Statistics and Actuarial Science and works with the Indonesian government and partner universities to offer joint programs. These programs include both cooperative education opportunities to build work experience and industry outreach to develop a pipeline of talent for the Indonesian economy. The global business partners are also integral when developing co-op opportunities and future job prospects for those students taking part in the READI project.

Partnerships such as this are only possible with the support of all parties. If the governments on either side were opposed to the collaboration or indifferent, it would not have the momentum to move forward. If the industry partners were not established, an essential piece of the project would be missing in the form of local and sector expertise and the loss of a recruitment partner for future actuarial talent. And, without the buy-in from the University of Waterloo or the seven partnering institutions in Indonesia, there would be no capacity to run an ongoing collaboration to promote and train the next generation of actuaries in Indonesia.

The READI project is an example of what can happen when government, industry and institutions of higher learning come together to solve a pressing problem that impacts thousands of lives when they need support the most. Every nation requires the right training and the right talent. Sharing knowledge and expertise from one institution to an international partner is at the heart of how international partnerships can make a positive impact and create long-lasting prosperity.

\section{International Work-Integrated Learning: Future of Global Talent}

Well-developed and well-executed international partnerships that universities take part in can fundamentally impact entire disciplines and industries. The collaboration of groundbreaking, fundamental research is only strengthened by complementary institutions working together and leveraging a global community of talented researchers.

At the heart of our institutions, despite all of the exceptional research that is done every day, our students and their growth are our top priority. Their development and future success will have an unprecedented impact on our world, but it is vital that universities leverage their global connections to offer their students a global experience that goes beyond student exchanges and joint degrees.

Work-integrated learning and experiential education have been instrumental in the development of students at the
University of Waterloo through its co-op program. As pointed out in the previous section on the READI program, it is even a sought-after aspect of that international project. This is because co-op offers students a unique opportunity to gain relevant work experience throughout their degree, build a number of valuable skills outside of the classroom and earn money to pay for their studies. These experiences also cut down on the learning curve students face when leaving their institution.

Building international work-integrated learning opportunities takes this even further by introducing all of the benefits cooperative education offers and combining them with the benefits of an exchange student's experience. There is no doubt that cooperative education and student exchange programs offer distinct benefits and opportunities [11]. It is the experience at the University of Waterloo that the development of truly global talent is found at the cross section of these two programs.

Establishing these experiences does not happen overnight and depends greatly on building international partnerships with businesses overseas. Creating the linkages with businesses needed to build the network of job opportunities open to students can be done through several approaches, and they come from fostering international collaboration with their own community. Universities of all sizes have connections outside of their country in the form of other partnering institutions and their alumni.

The University of Waterloo, which was founded in 1957 has more than 15,000 alumni outside of Canada in 145 countries. These international members of the Waterloo community prove to be essential in the global expansion of co-op job opportunities, regardless of whether they are in roles that allow them to hire students for co-op positions. These alumni are advocates for a co-op at the company overseas and can act as an outpost for future placement opportunities. Moreover, the existing international partnerships the universities have with other institutions can play a significant role in developing international work-integrated learning opportunities as the students can work in research labs or on those research projects that have joint partnerships with private enterprises.

It is important to note that international experiences through experiential education should not be limited to domestic students, but to all students. There is a natural inclination to view international work placements as something domestic students seek out since international students are already taking part in an international exchange program [12]. In our experience at the University of Waterloo, this is not true.

The University of Waterloo attracts thousands of international students to our campus, not only because of our research and educational strengths but also because of our co-op program. These types of international placements 
happen every term and every year. One recent international co-op experience involved an international student who originally came to Waterloo from India did his co-op work term at a research lab at a partnering university in China and collaborated with one of his colleagues in China to together develop their own startup venture after completing their degrees.

This student embodies what is possible when international collaborations are combined with the power of work-integrated learning. Developing the connections, global perspective and work experience needed to inspire a transnational startup venture, by the student's own admission, could not have happened for him in India. The connections we make and the prospects that they create are only possible when we explore what is possible.

These opportunities show students that their impact can be on more than a single city or country, but on a global scale. They are opened up to a new culture and a new way of thinking that goes far beyond a classroom. The future of our world is a global one, and the right talent is needed to lead to that future. Future leaders must possess not only exceptional technical skills, but also the ability to look at problems through a global lens. Only then will we have the capability and capacity to create long-term prosperity for our world.

\section{Conclusion}

Partnerships offer the benefit of possibility. More ideas, resources and expertise create more opportunities for groundbreaking discoveries and the broadening of the perspectives and knowledge base of those students who take part in international experiences. These actions of institutional cooperation are integral as we look to tackle countless global challenges. Universities that limit their view of partnerships to domestic partners limit what is possible and the impact of their community of students, faculty and graduates.

Collaborations can mean many different things to many universities. To build a global network of partnerships that will lead to a prosperous twenty-first century, it would be advantageous for universities worldwide to take a holistic approach and explore the wide range of opportunities open to their institutions. There is no single area of collaboration, whether it be research, student exchange or entrepreneurship that will create the impact we need to solve the global challenges in front of us.

University education is no longer built on the learning from a handful of classrooms and instructors in an isolated campus cut-off from society. Society and the global economy are best served when our universities and their community of students, scholars and staff members branch out to develop international partners that multiply impact and opportunities to shape a more prosperous future, domestically and globally.

As certain nations in the world, out of fear, look inward instead of outward to build prosperity, our world is limited. Instead, we can set a different example for the global landscape and work together through cohesive and mutually beneficial partnerships. We are only limited by our institutions' drive and determination, and universities can and should be central to this movement. We are stronger when we work together, and with all the opportunities out there still to be seized, now is the time for universities to look across borders, cultures and disciplines to create lines of communication and collaboration.

\section{References}

1. Knight, J., \& De Wit, H. (2018). Internationalization of higher education: Past and future. International Higher Education, 95, $2-$ 4. https://doi.org/10.6017/ihe.2018.95.10715.

2. Walters, R. How to attract and retain the right talent to grow business internationally. https://www.robertwalters.cn/a-guide-forasian-companies.html. Accessed March 28, 2019.

3. European Commission. (2014). Effects of mobility on the skills and employability of students and the internationalisation of higher education institutions. The Erasmus Impact Study. https://doi.org/ $10.2766 / 75468$.

4. Lee, Y. S. (2000). The sustainability of university-industry research collaboration: An empirical assessment. The Journal of Technology Transfer, 25, 111. https://doi.org/10.1023/A:1007895 322042.

5. Bramwell, A., \& Wolfe, A. D. (2008). Universities and regional economic development: The entrepreneurial University of Waterloo. Research Policy, 37(8), 1175-1187. https://doi.org/10.1016/j. respol.2008.04.016.

6. United Nations Educational, Scientific and Cultural Organization. (2017). Policy paper: Six ways to ensure higher education leaves no one behind (Vol. 30). Global education monitoring report. http://unesdoc.unesco.org/images/0024/002478/247862E.pdf.

7. Banks, C., Siebe-Herbig, B., \& Norton, K. (2016). Global perspectives on strategic international partnerships: A guide to building sustainable academic linkages. New York: Institute of International Education.

8. Waterloo Institute for Nanotechnology, International partnerships, WIN-Soochow University (SUN), Institute for Functional Nanoand Soft-Materials (FUNSOM), \& The College of Nanoscience and Technology (CNST). https://uwaterloo.ca/institutenanotechnology/partnership-and-collaboration/international/china. Accessed March 28, 2019.

9. Sustainable Development Solutions Network (SDSN) Canada, Network Members. https://uwaterloo.ca/sustainable-developmentsolutions-network-canada/network-members. Accessed March 28, 2019.

10. Risk Management, Economic Sustainability, and Actuarial Science Development in Indonesia. https://uwaterloo.ca/risk-managementeconomic-sustainability-actuarial-science-development-indonesia/. Accessed March 28, 2019.

11. McRae, N., Ramji, K., Lu, L., \& Lesperance, M. (2016). Developing global-ready graduates: The CANEU-COOP experience. Asia-Pacific Journal of Cooperative Education, 17(4), 377386. https://eric.ed.gov/?id=EJ1131552. 
12. Gribble, C., \& McRae, N. (2017). Creating a climate for global WIL: Barriers to participation and strategies for enhancing international students' involvement in WIL in Canada and Australia. In G. Barton \& K. Hartwig (Eds.), Professional learning in the work place for international students. Professional and practice-based learning (pp. 35-55). Cham, Switzerland: Springer. https://doi.org/10.1007/978-3-319-60058-1.
Open Access This chapter is licensed under the terms of the Creative Commons Attribution 4.0 International License (http:// creativecommons.org/licenses/by/4.0/), which permits use, sharing, adaptation, distribution and reproduction in any medium or format, as long as you give appropriate credit to the original author(s) and the source, provide a link to the Creative Commons license and indicate if changes were made.
The images or other third party material in this chapter are included in the chapter's Creative Commons license, unless indicated otherwise in a credit line to the material. If material is not included in the chapter's Creative Commons license and your intended use is not permitted by statutory regulation or exceeds the permitted use, you will need to obtain permission directly from the copyright holder. 